\title{
Noscapine protects OLN-93 oligodendrocytes from ischemia-reperfusion damage: Calcium and nitric oxide involvement
}

\author{
S Nadjafi, S-A Ebrahimi, N Rahbar-Roshandel \\ Faculty of Medicine, Iran University of Medical Sciences, Tehran, Iran
}

Received: May 26, 2014

Accepted: July 31, 2015

\begin{abstract}
This study was carried out to evaluate the effects of noscapine, a benzylisoquinoline alkaloid from opium poppy, on oligodendrocyte during ischemia/reperfusion-induced excitotoxic injury. Changes in intracellular calcium levels due to chemical ischemia and nitric oxide (NO) production during ischemia/reperfusion were evaluated as the hallmarks of ischemia-derived excitotoxic event. OLN-93 cell line (a permanent immature rat oligodendrocyte) was used as a model of oligodendrocyte. 30- or 60-minute-oxygen-glucose deprivation/24 hours reperfusion were used to induce excitotoxicity. MTT (3-[4,5-Dimethylthiazol-2-yl]-2,5-diphenyl-tetrazolium bromide) assay was used to evaluate cell viability. Ratiometric fluorescence microscopy using $\mathrm{Ca}^{2+}$-sensitive indicator Fura-2/AM was utilized to assess intracellular calcium levels. NO production was evaluated by Griess method. Noscapine $(4 \mu \mathrm{M})$ significantly attenuated intracellular $\mathrm{Ca}^{2+}$ elevation $(P<0.001)$. Also, noscapine significantly decreased $\mathrm{NO}$ production during a 30 -minute oxygen-glucose deprivation/reperfusion $(P<0.01)$. The inhibitory effect of noscapine $(4 \mu \mathrm{M})$ on intracellular $\mathrm{Ca}^{2+}$ was greater than ionotropic glutamate receptors antagonists. Noscapine is protective against ischemia/reperfusion-induced excitotoxic injury in OLN-93 oligodendrocyte. This protective effect seems to be related to attenuation of intracellular $\mathrm{Ca}^{2+}$ overload and $\mathrm{NO}$ production.
\end{abstract}

Keywords: noscapine, oligodendrocyte, OLN-93 cell line, oxygen-glucose-deprivation, calcium, nitric oxide

Noscapine is a benzylisoquinoline alkaloid derived from opium poppy (Papaver somniferum) $(5,61)$. Noscapine, with very few side effects and no addiction liability, has been used as an antitussive drug for many years $(30,48)$. Recently, it has been demonstrated that noscapine is a tubulin-binding, anti-angiogenic anticancer drug, which effectively inhibits the progression of various cancer types both in vitro and in vivo with no evident side effects $(30,48)$. Furthermore, noscapine induces apoptosis dose-dependently in high concentrations (12). The important effects of noscapine on reducing the extent of ischemic brain injury in an animal model and mortality rate in stroke patients were demonstrated by Mahmoudian et al. in two separate studies $(31,32)$.

Oligodendrocytes, the myelinating cells, are particularly vulnerable to ischemic shock and glutamate excitotoxic damage $(10,36)$, associated with acute and chronic diseases affecting white matter such as stroke and multiple sclerosis (MS) $(10,56)$.

Excitotoxicity is a phenomenon whereby overactivation of ionotropic glutamate receptors (GluRs) provokes cell death and the intracellular $\mathrm{Ca}^{2+}$ overload appears to be the

Corresponding author: Nahid Rahbar-Roshandel

Department of Pharmacology, Iran University of Medical Sciences, Tehran, Iran

Phone: +98 21 88058696; Fax: +98 21 88052978; E-mail: nrahbar@sina.tums.ac.ir 
main part of this lethal event $(36,38)$. Among three types of ionotropic glutamate receptors, $\mathrm{N}$-methyl-D-aspartate (NMDA) receptors have the major role in neuronal excitotoxicity although $\alpha$-amino-3-hydroxy-5-methyl-4-isoxazole propionic acid (AMPA), and kainate (KA) receptors have been implicated as well $(18,36)$. In oligodendrocytes, the major cell type of white matter, which are extremely vulnerable to excitotoxic and ischemic insult, NMDA receptors are expressed in clusters on oligodendroglial processes while AMPA and kainate receptors are distributed on oligodendrocyte somata $(10,34)$. Particularly, immature oligodendrocytes are found to be even more sensitive to ischemic injury than their more mature correlates (37).

NMDA receptors are the main route of $\mathrm{Ca}^{2+}$ influx, but changes in molecular characteristics of AMPA/kainate receptors in oligodendrocytes, may cause additional permeability to $\mathrm{Ca}^{2+}$, and enhance sensitivity of oligodendrocytes to excitotoxic insult (34, 36). For example, lack of the GluR2 subunit of AMPA receptors in differentiated oligodendrocytes and expression of the edited GluR6 subunit in low extent in oligodendroglial cells make these receptors more permeable to $\mathrm{Ca}^{2+}(36)$.

Nitric oxide (NO) mediates various normal physiologic functions as a messenger molecule (20). Different isoforms of nitric oxide synthase (NOS) produce NO. For instance, neuronal NOS (nNOS) is present exclusively in neurons and the inducible NOS (iNOS) can be activated in glial cells; iNOS and nNOS are present in oligodendrocytes $(59,60)$. Other than the physiological actions, NO can cause cellular damage and act as a key mediator of neurodegeneration in many diseases, including Parkinson's disease, Alzheimer's disease, amyotrophic lateral sclerosis, Huntington's disease, and stroke (20). Moreover, there is the evidence for association of nNOS activation with the loss of oligodendrocytes and demyelination $(59,60)$.

OLN-93 cell line is used as a model of oligodendrocytes for in vitro studies; the OLN-93 cells based on their morphological and antigenic characteristics are comparable to 5- to 10-day-old (postnatal time) cultured rat brain oligodendrocytes, so this cell line is identified as immature oligodendrocyte $(4,43,58)$.

This study was designed to verify if noscapine could protect OLN-93 oligodendrocytes against oxygen-glucose deprivation/reperfusion-induced excitotoxicity. Besides, intracellular calcium levels during chemical ischemia, and NO production after ischemia/reperfusion were evaluated as important factors involved in ischemia-induced excitotoxic event.

\section{Materials and Methods}

\section{Materials}

Noscapine was obtained from Sigma Chemical Co. (St. Louis, MO, USA). The stock solution was prepared at $1 \mathrm{mmol} / \mathrm{l}$ in dimethylsulfoxide (DMSO) and kept at $-20{ }^{\circ} \mathrm{C}$. Dulbecco's Modified Eagle's medium (DMEM) with glutamine, glucose/glutamine-free DMEM, fetal bovine serum (FBS) were purchased from GIBCO. Penicillin-streptomycin, 3-[4,5-Dimethylthiazol-2-yl]-2,5-diphenyl-tetrazolium bromide (MTT), poly-L-lysine, Dizocilpine (MK-801), 2,3-dihydroxy-6-nitro-7-sulfamoyl-benzo(f)quinoxaline-2,3-dione (NBQX), $\mathrm{N}^{\mathrm{G}}$ nitro-L-arginine methyl ester (L-NAME), modified Griess reagent, and Fura 2-AM were purchased from Sigma Chemical Co. (St. Louis, MO, USA). All other chemicals are of the purest grade available from regular commercial sources. 


\section{Cell culture}

OLN-93 cell line was purchased from Pasteur Institute of Iran (Tehran, Iran). The cells were grown in DMEM medium supplemented with 10\% FBS and $100 \mathrm{IU} / \mathrm{ml}$ penicillin and 100 $\mu \mathrm{g} / \mathrm{ml}$ streptomycin in a humidified $95 \%$ air and $5 \% \mathrm{CO}_{2}$ incubator at $37{ }^{\circ} \mathrm{C}$. The cells were sub-cultured twice a week by gentle scraping and were cultured on poly-L-lysine-coated 12 -well plates at a density of $5 \times 10^{4}$. Culture dishes were coated with poly-L-lysine 24 hours before the experiment. Poly-L-lysine (150 000-300 $000 \mathrm{MW}$ ) was dissolved in deionized water and the plate wells were filled with this solution $(20 \mu \mathrm{g} / \mathrm{ml})$. After 5 minutes standing at room temperature, the solution was aspirated and the plates were left to dry in a laminar flow hood overnight. Cells were used for experiments 24 hours after seeding.

\section{Oxygen-glucose deprivation and drug exposure}

Ischemia/ reperfusion is a well established model in in vitro, in vivo and ex vivo pharmacological studies to evaluate the effects of drugs in different cell types such as neural, renal and cardiac cells or organs $(14,19,25,26,47,52,53,55)$. For instance, brief or lethal episodes of ischemia/reperfusion are useful methods in cardioprotection studies (11).

Procedures for oxygen-glucose deprivation (OGD) were performed as described previously (9). Briefly, the culture medium was replaced with glucose/glutamine-free DMEM, and cells were exposed to hypoxia for 30 and 60 minutes in a small anaerobic chamber filled with $95 \%(\mathrm{v} / \mathrm{v}) \mathrm{N}_{2}$ and $5 \%(\mathrm{v} / \mathrm{v}) \mathrm{CO}_{2}$ at $37{ }^{\circ} \mathrm{C}$. To terminate the oxygenglucose deprivation, the chamber was opened and the medium was replaced with DMEM, and the cultures were then placed in an incubator with $5 \% \mathrm{CO}_{2}$ for 24 hours. To examine the drug effects, cell cultures were treated 3 hours before oxygen-glucose deprivation with noscapine, at concentrations of $1-5 \mu \mathrm{M}$. The pre-incubation time of 3 hours was selected based upon previous studies (42). These concentrations were chosen based on the results of preliminary experiments at nontoxic levels of noscapine (data not shown). To investigate the effects of various inhibitors on oxygen-glucose deprivation-induced cell death, MK-801, a non-competitive antagonist of the NMDA receptor or NBQX, an AMPA/kainate receptor antagonist, was added to the medium 3 hours before oxygen-glucose deprivation (52). Plates not exposed to oxygen-glucose deprivation were used as external control and those exposed to oxygen-glucose deprivation conditions without the addition of any drug were used as internal control. All measurements were duplicated and each experiment was repeated at least three times. Every data point is therefore the mean of at least six measurements.

\section{Analysis of cell viability}

Oligodendroglial cell viability was measured using the colorimetric MTT assay, as previously described by Mosmann (40). Briefly, cells were incubated with $0.5 \mathrm{mg} / \mathrm{ml} \mathrm{MTT} \mathrm{in} \mathrm{DMEM,}$ at $37{ }^{\circ} \mathrm{C}$ under $5 \% \mathrm{CO}_{2}$, for 3 hours. The blue formazan reduction product, produced by the action of succinate dehydrogenase in living cells on the dye, was dissolved in $100 \mu 1 \mathrm{DMSO}$, and the optical density was read at $570 \mathrm{~nm}$ using a Dynex MRX microplate reader (Dynex, Richfield, MN, USA). Data were expressed as the percentage of viable cells in oxygenglucose deprivation-exposed plates compared with control normoxic plates determined by MTT reduction. 
Measurement of intracellular free calcium

Measurement of intracellular free calcium concentration was performed using a $\mathrm{Ca}^{2+}$ sensitive indicator Fura 2-AM on an Olympus IX-71 inverted microscope and CCD camera. Fluorescence emission images of intracellular Fura-2 at $510 \mathrm{~nm}$, after excitation at two different wavelengths, i.e. 340 and $380 \mathrm{~nm}$, were acquired (54). Ratiometric analysis of image pairs was carried out using Image J (National Institute of Health (NIH), Bethesda, Maryland, USA), and Excel (Microsoft; Seattle, WA, USA) softwares (44). Sodium azide $\left(\mathrm{NaN}_{3}\right)$, a specific inhibitor of complex IV, is well accepted to induce chemical hypoxia in vitro and in vivo $(28,62)$. Moreover, the chemical hypoxia induced by mitochondrial toxins produces a secondary excitotoxicity, leading to the activation of NMDA receptors. Therefore, sodium azide, as an inhibitor of cytochrome oxidase, induces the release of excitotoxins via energy impairment, so this results in neurodegeneration (21). Also, the analysis of cell viability by MTT assay demonstrated that sodium azide by inducing mitochondrial dysfunction could provide a common platform for investigating the mechanisms of both ischemic and degenerative neuronal damage, useful for testing potential protective agents against neuronal death (46).

OLN-93 oligodendrocytes were pre-incubated for 30 minutes with Fura-2 AM (5 $\mu \mathrm{M})$ at room temperature. Incubation was continued for a further 15 minutes at $37{ }^{\circ} \mathrm{C}(44)$. Cells were placed in a flow-chamber and washed with isotonic buffer containing (in $\mathrm{mM}$ ): 128 $\mathrm{NaCl}, 2.5 \mathrm{KCl}, 2 \mathrm{CaCl}_{2}, 1 \mathrm{MgCl}_{2}, 10$ glucose and 10 HEPES, pH 7.4 for 10 minutes $(1,16)$. The flow rate was $0.5 \mathrm{ml} / \mathrm{min}$ and the temperature was kept at $37{ }^{\circ} \mathrm{C}$. Chemical oxygenglucose deprivation was started by flow of sodium azide $\left(\mathrm{NaN}_{3}: 20 \mathrm{mM}\right)$ in glucose free isotonic buffer for 30 minutes $(33,57,62)$. The concentration of sodium azide $(20 \mathrm{mM})$ was selected based on the study by Marino et al. (33). Our experiments showed that this concentration produced a significant elevation of intracellular calcium in OLN-93 cells through 30 minute-chemical oxygen-glucose deprivation. Images were taken for 4-minutedurations along with 10-minute pauses at start, middle and the end of 30 minutes chemical oxygen-glucose deprivation. Noscapine and other drugs were dissolved in sodium azide (20 $\mathrm{mM}$ ) to evaluate the alteration of intracellular calcium levels in the presence and absence of drugs during 30 minutes of chemical oxygen-glucose deprivation.

\section{Measurement of nitrite}

The level of nitrite as a measure of NO production in the culture medium was quantified using modified Griess reagent. In brief, the medium in each well was removed and centrifuged at $10000 \times \mathrm{rpm}$ for 10 minutes at $4{ }^{\circ} \mathrm{C}$. Then, the supernatant was mixed with an equal volume of modified Griess reagent at room temperature for 10 minutes, and the absorbance was measured at $540 \mathrm{~nm}$ using an Ultrospec ${ }^{\circledR} 3000 \mathrm{UV} /$ Visible spectrophotometer (Pharmacia Biotech, Cambridge, England). The nitrite concentration was determined from a sodium nitrite standard curve. Plates not exposed to oxygen-glucose deprivation were used as external control and those exposed to oxygen-glucose deprivation conditions without the addition of any drug were used as internal control.

\section{Statistical analysis}

All results are expressed as mean $\pm \mathrm{SD}$. The significance of differences was evaluated using Student's $t$-test by Excel 2007 (Microsoft; Seattle, WA, USA) software. For multiple comparisons we used One Way ANOVA (Tukey's post hoc) using SPSS 16 (International Business Machines Corporation, 1 New Orchard Road Armonk, New York 10504-1722, USA). $P$ value of $<0.05$ was considered statistically significant. 


\section{Results}

The effects of noscapine, on oxygen-glucose deprivation/reperfusion-induced cell injury in OLN-93 cells

MTT assay demonstrated that cell viability decreased to $52 \%$ and $40 \%$ during 30 (Fig. 1A) and 60 minutes (Fig. 1B) oxygen-glucose deprivation/reperfusion, respectively. Pretreatment of cultures with noscapine $(1-5 \mu \mathrm{M})$, significantly attenuated oxygen-glucose deprivationinduced cell injury in OLN-93 cells in a concentration-dependent manner $(P<0.001)$. The peak of protective effect was at $4 \mu \mathrm{M}$ for noscapine through the time-scheduled experiments. At this concentration, noscapine increased cell viability to $79 \%$ and $69 \%$, during 30 and 60 minutes of oxygen-glucose deprivation/reperfusion, respectively $(P<0.001)$.


Fig. 1. The effects of noscapine (1-5 $\mu \mathrm{M})$, MK-801 $(10 \mu \mathrm{M})$, NBQX $(30 \mu \mathrm{M})$, and L-NAME $(100 \mu \mathrm{M})$ on oxygen-glucose deprivation/24 hours reperfusion-induced cell injury in cultured OLN-93 oligodendrocytes. Optical density (OD) at $570 \mathrm{~nm}$ corresponds to the blue formazan reduction product which is produced by the action of mitochondrial succinate dehydrogenase in living cells and correlates to cell viability. The control normoxic plates were considered as $100 \%$ viability and those exposed to oxygen-glucose deprivation conditions without the addition of any drug were used as internal control. Data are expressed as mean percentage of viable cells (SD) in oxygen-glucose deprivation-exposed plates compared with internal control $(* * * P<0.001)$.

(A) Cell viability after 30 minutes of oxygen-glucose deprivation/24 hours reperfusion.

(B) Cell viability after 60 minutes of oxygen-glucose deprivation/24 hours reperfusion 
The effects of MK-801, NBQX and L-NAME on oxygen-glucose deprivation/reperfusioninduced cell injury in OLN-93 cells

To evaluate the effects of inhibitors of ionotropic glutamate receptors on ischemia/reperfusioninduced cell death, cells were treated with MK-801 $(10 \mu \mathrm{M})$ and NBQX $(30 \mu \mathrm{M}) 3$ hours before oxygen-glucose deprivation. Our results revealed that MK-801 and NBQX could significantly protect the OLN-93 cells from oxygen-glucose deprivation-induced cell death during both time-scheduled assessments in comparison with internal control $(P<0.001)$. MK-801 increased cell viability to $69 \%$ and $63 \%$ during 30 and 60 minutes of oxygenglucose deprivation/reperfusion, respectively. Moreover, NBQX improved cell viability to $67 \%$ and $65 \%$ during same time-scheduled assessments, respectively. Furthermore, L-NAME $(100 \mu \mathrm{M})$, a NOS inhibitor, increased cell viability to $76 \%$ after 30 minutes of oxygenglucose deprivation/reperfusion (Fig. 1A, B).

The effects of noscapine, MK-801 and NBQX on intracellular calcium levels during a 30-minute chemical oxygen-glucose deprivation in OLN-93 cells

To determine the intracellular calcium levels during ischemia, the OLN-93 cells were exposed to sodium azide $\left(\mathrm{NaN}_{3}: 20 \mathrm{mM}\right)$, as a model of chemical oxygen-glucose deprivation, for 30 minutes. Sodium azide was able to induce $135 \%$ increase in intracellular $\mathrm{Ca}^{2+}$ concentration which was statistically significant compared with baseline. Furthermore, the ischemiaevoked increase in intracellular $\mathrm{Ca}^{2+}$ levels was decreased to $117 \%$ by noscapine $(4 \mu \mathrm{M})$, $121 \%$ by MK-801 $(10 \mu \mathrm{M})$ and $127 \%$ in the presence of NBQX $(30 \mu \mathrm{M})$ compared to preoxygen-glucose deprivation levels. Reduction in intracellular $\mathrm{Ca}^{2+}$ levels in the presence of noscapine or ionotropic glutamate receptors inhibitors was significant in comparison with chemical oxygen-glucose deprivation in absence of these drugs $(P<0.001)$ (Fig. 2).

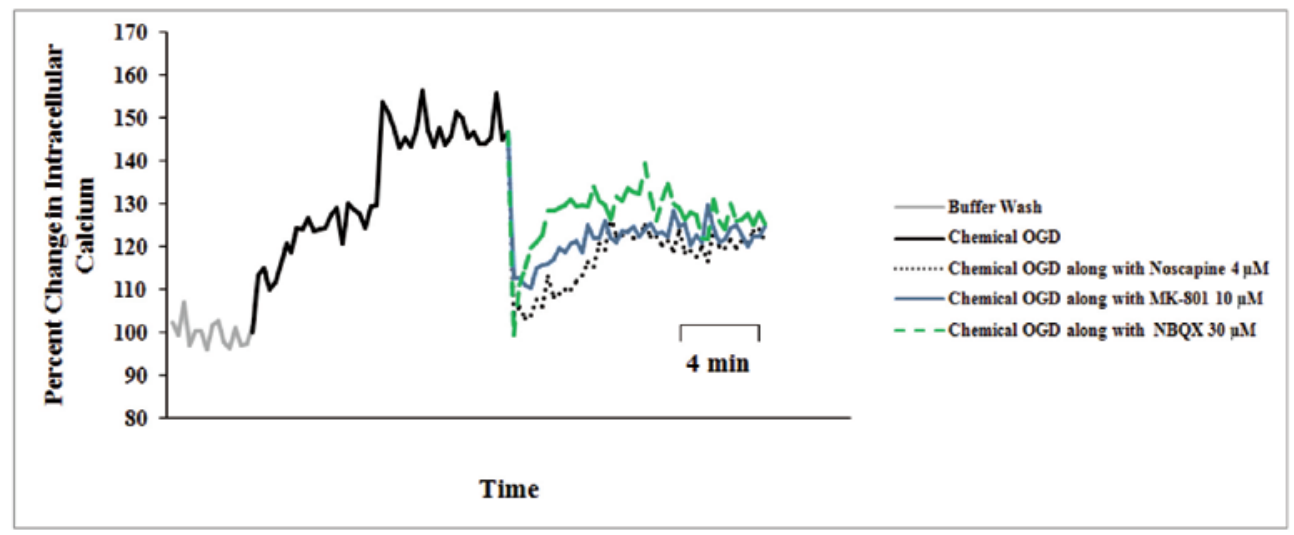

Fig. 2. Assessment of intracellular $\mathrm{Ca}^{2+}$ during 30-minute chemical oxygen-glucose deprivation (OGD) in OLN-93 oligodendrocytes. Typical results based on Fura 2-AM fluorescence ratio (F340 nm/F380 nm) to evaluate the intracellular $\mathrm{Ca}^{2+}$ levels during 30-minute chemical OGD by sodium azide (NaN3: $20 \mathrm{mM}$ ). All the procedures were performed in $\mathrm{Ca}^{2+}$-containing incubation buffer. The cells were incubated with Fura 2-AM. The images were taken in 4-minute durations fallowed by 10 minute-pauses during chemical OGD to evaluate the alteration of intracellular $\mathrm{Ca}^{2+}$ levels. The basic level of intracellular $\mathrm{Ca}^{2+}$ during buffer wash was considered $100 \%$. Sodium azide induced an increase in intracellular $\mathrm{Ca}^{2+}$ levels, an effect that was reduced by noscapine $(4 \mu \mathrm{M}), \mathrm{MK}-801(10 \mu \mathrm{M})$ and NBQX $(30 \mu \mathrm{M})(P<0.001)$ 
The effects of noscapine, L-NAME and MK-801 on nitric oxide production during 30-minute oxygen-glucose deprivation/reperfusion in OLN-93 cells

NO production in the culture medium was measured by modified Griess reagent after 30 minutes oxygen-glucose deprivation/reperfusion. Exposure of OLN-93 cells to 30 minutes of oxygen-glucose deprivation/reperfusion significantly increased nitrite production compared with the external control $(P<0.001)$. Pretreatment of cultures with noscapine $(4 \mu \mathrm{M})$, significantly decreased NO production, as compared with the oxygen-glucose deprivation control $(P<0.01)$. The effects of L-NAME $(100 \mu \mathrm{M})$, a NOS inhibitor, and MK-801 (10 $\mu \mathrm{M})$, a non-competitive antagonist of the NMDA receptor, on NO production were also evaluated, and both compounds reduced the NO production, significantly $(P<0.001 ; P<$ 0.01, respectively) (Fig. 3).

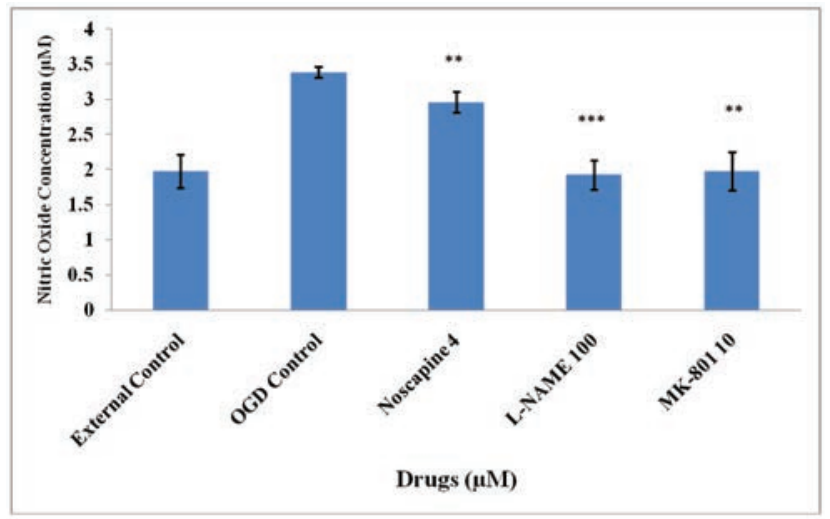

Fig. 3. The effects of noscapine $(4 \mu \mathrm{M})$, L-NAME $(100 \mu \mathrm{M})$, and MK-801 $(10 \mu \mathrm{M})$ on nitric oxide (NO) production during a 30-minute oxygen-glucose deprivation (OGD)/24 hours reperfusion-induced cell injury in cultured OLN-93 oligodendrocytes. The plates not exposed to oxygen-glucose deprivation were used as external control and those exposed to oxygen-glucose deprivation conditions without the addition of any drug were used as OGD control. The values are presented as mean (SD) compared with OGD control.

$$
(* * P<0.01 ; * * * P<0.001)
$$

\section{Discussion}

Noscapine, a nontoxic natural compound, was most known for its antitussive effect $(27,61)$. Various studies reported dual effects for noscapine. For the first time, Joshi et al. showed it had potent anti-tumor activity for which it is already in Phase I/II clinical trials $(27,61)$. In this regard, noscapine induced cytotoxic effects on myeloid leukemia cells that were treated for 72 hours in the presence of different high concentrations of noscapine (i.e. $>5 \mu \mathrm{M}$ ) and is capable to induce apoptosis (12). However, noscapine has several protective effects in non-toxic concentrations. Noscapine as an antitussive compound in low concentrations (i.e. $<1 \mu \mathrm{M})$ presented a specific antagonistic effect on bradykinin receptors through bradykinininduced smooth muscle contraction in the isolated ileum of the guinea-pig (29). Mahmoudian et al. presented the usefulness of noscapine in decreasing the extent of brain injury after hypoxic-ischemic damage in neonatal rats (32). Moreover, through a clinical trial, they show that the oral administration of noscapine to the acute ischemic stroke patients effectively improved clinical prognosis and reduced mortality without any specific side effects (31). 
Also, Hiser et al. revealed that noscapine could protect against vincristine-derived demyelination in cell cultures containing neurons, astrocytes, and oligodendrocytes (13).

In this study, we evaluated the effect of noscapine on OLN-93 oligodendrocytes during 30 or 60 minutes oxygen-glucose deprivation followed by 24 hours reperfusion. The alteration of intracellular calcium levels during a 30-minute chemical ischemia, and nitric oxide production after 30 minutes oxygen-glucose deprivation/reperfusion were assessed.

Oligodendroglial damage due to excitotoxicity is a main point in demyelinating diseases such as multiple sclerosis, and an important factor in ischemic injuries such as stroke $(34,38$, 45). It has been known that immature and differentiated oligodendrocytes in vitro are the most susceptible cells of the white matter to transient oxygen and glucose deprivation (35). Notably, during simulated ischemia, NMDA and AMPA/kainate receptors, based on their locations, both take part in producing $\mathrm{Ca}^{2+}$-dependent injury in processes and somata of oligodendroglial cells (45). All in all, calcium ions are the mediator of excitotoxicity in oligodendrocytes $(7,35,45)$.

The results of MTT assay revealed that, noscapine could significantly protect the OLN93 cells from ischemia/reperfusion-induced injury in a concentration dependent manner through time-scheduled assessments. Our results are in accord with the findings of previous studies, which pointed to the effectiveness of noscapine on hypoxic-ischemic insults $(31,32)$. Moreover, MK-801 and NBQX, antagonists of ionotropic glutamate receptors, significantly protected the OLN-93 oligodendrocytes against oxygen-glucose deprivation/reperfusioninduced damage. Formerly, it was believed that oligodendrocytes lack the NMDA-ionotropic glutamate receptors, and they merely present the AMPA/kainate receptors, but there is increasing evidence of the presence of NMDA receptors as well $(6,23,37,41)$. In late 2005, it was clarified that, AMPA and kainate receptors are expressed on the cell body of the oligodendrocytes, and NMDA receptors are found on the distal processes of the oligodendroglial cells and myelin $(15,45)$. Salter and Fern explained that the blockade of AMPA/kainate and NMDA receptors could protect oligodendroglial cells against $\mathrm{Ca}^{2+}$ dependent injury through oxygen glucose deprivation (45). The results of this study are in accord with the Salter and Fern's findings and confirmed the protective effect of ionotropic glutamate receptors antagonists against ischemia-induced injury in oligodendrocytes.

Furthermore, our results indicated that MK-801 was more effective than NBQX on cell protection during 30 minutes of oxygen-glucose deprivation/reperfusion. In a 60-minute oxygen-glucose deprivation, application of the same concentrations of MK-801 and NBQX resulted in a more protective effect of NBQX than that of MK-801. This is consistent with previous findings on cortical neurons, that indicated that AMPA-kainate receptors modulate a more slowly-triggered excitatoxic injury than NMDA receptors do $(8,22,52)$. Interestingly, noscapine at $4 \mu \mathrm{M}$ had greater protective effect than ionotropic glutamate receptors antagonists in both the 30- and 60-minute-scheduled oxygen-glucose deprivation/reperfusion experiments. This indicates that other mechanisms may be involved in protective effects of noscapine.

Next, we intended to know if the protective effect of noscapine was associated with alteration in intracellular $\mathrm{Ca}^{2+}$ overload and NO production. Therefore, we selected the 30 -minute courses of chemical ischemia and oxygen-glucose deprivation/reperfusion to determine the intracellular $\mathrm{Ca}^{2+}$ levels and NO production.

In this study, chemical oxygen-glucose deprivation by sodium azide and $\mathrm{Ca}^{2+}$-sensitive indicator Fura-2/AM were used to assess intracellular calcium levels.

Sodium azide $\left(\mathrm{NaN}_{3}\right)$, a well-accepted specific inhibitor of complex IV, has been used to induce chemical hypoxia both in vitro and in vivo $(28,62)$. In vitro model of brain ischemia 
by sodium azide increased intracellular $\mathrm{Ca}^{2+}$ in neurons (33). It has been demonstrated that, in this model the dominant source of calcium elevation is extracellular, comprising glutamate receptor activation in a first phase and calcium channel opening in a second phase (33). Thus, we applied sodium azide in glucose free isotonic buffer to assess the intracellular $\mathrm{Ca}^{2+}$ overload in OLN-93 oligodendrocytes.

The results showed that the significant rise in intracellular $\mathrm{Ca}^{2+}$ levels due to 30 minutesodium azide challenge was attenuated significantly by noscapine. Also, MK-801 and NBQX significantly decreased the intracellular calcium levels in this condition. Interestingly, the effects of noscapine on intracellular $\mathrm{Ca}^{2+}$ levels were significantly greater compared with ionotropic glutamate receptors antagonists. The findings of MTT assay from the 30-minuteoxygen-glucose deprivation/reperfusion experiment were confirmed by the results of intracellular $\mathrm{Ca}^{2+}$ levels assessment; thus, reduction of the intracellular $\mathrm{Ca}^{2+}$ overload by noscapine seems to be important in protecting of ONL-93 cells during ischemia-induced excitotoxic injury.

Nitric oxide has an important function in excitotoxic pathways mediated by NMDA Ca ${ }^{2+}$ channels (20). In neurons, nNOS is partly bound close to the NMDA receptor, and is activated by calcium entry via the receptor-gated ion channel (2). In vitro studies demonstrated that NMDA-induced neurotoxicity was decreased by NOS inhibitors, was also dampened in neurons isolated from $\mathrm{nNOS}^{-/}$mice (2). In addition, in vivo damage induced by a model of brain ischemia was reduced by treatment with NOS inhibitors in $\mathrm{nNOS}^{-/-}$mice (2). This evidence suggests that nNOS activation, because of NMDA receptor activation, might contribute to neuronal excitotoxic death (2).

There are few studies about the role of nitric oxide during excitotoxicity in oligodendrocytes. Markedly, Kaur et al. indicated that excitotoxicity and nitric oxide are involved in periventricular white matter (corpus callosum) damage in response to hypoxia (17). Their investigations on neonatal brain of Wistar rats demonstrated that the up-regulation of mRNA and protein expression of three kinds of nitric oxide synthase: eNOS, nNOS and iNOS could be detected in corpus callosum in response to hypoxia (17). In addition, NO levels were significantly elevated in hypoxic rats up to 14 days after hypoxic exposure (17).

In this study, the Griess method was used to survey the role of noscapine on NO production induced by short-term oxygen-glucose deprivation /reperfusion. This study showed that 30 minutes ischemia/reperfusion could significantly increase NO production compared with external control. Besides, our findings revealed that noscapine could significantly reduce the NO production during 30 minutes of oxygen-glucose deprivation/ reperfusion indicating that attenuation of $\mathrm{NO}$ production may be one of the features of protective effect by noscapine during excitotoxicity. Furthermore, L-NAME, the NOS inhibitor, and MK-801, the non-competitive NMDA receptor antagonist, significantly decreased NO production during same assessments. The reduction of NO production by L-NAME and MK-801 were stronger comparing with noscapine. Although noscapine significantly decreased NO production, it could not attenuate the NO level to the level of the external control. Nevertheless, both L-NAME and MK-801 attenuated NO production to the level of external control, and there was not a significant difference between L-NAME and MK-801 in this effect. It seems that NO production in oligodendrocytes may be similar to neurons, in which NMDA receptor is linked to nNOS, and activation of nNOS leads to the production of NO and reactive oxygen species, which leads to cell death (51). Previous studies have also indicated that NOS inhibitors could noticeably reduce NO production after NMDA receptor activation, and decrease excitotoxic injury in cultured neurons $(24,39,52)$. Other studies on toll-like receptors (TLRs) suggested related findings. TLRs receptors, 
expressed mainly in sentinel cells of the immune system (50), also have important functions in oligodendrocytes $(3,49)$. Yao et al. through the in vitro and in vivo investigations on TLR mediated injury of demyelination by lipopolysaccharide, showed the involvement of increased NO production, and more importantly, a susceptibility of the oligodendrocytes to NO-mediated cell death by the activation of nNOS but not of iNOS $(59,60)$.

Considering the potent protective effects of noscapine compared with NMDA and AMPA/kainate antagonists, and its potent effect in attenuation of intracellular $\mathrm{Ca}^{2+}$ levels in contrast to the weaker action on prevention of NO production, it is suggested that the protective effect of noscapine may be due to its inhibitory effect on intracellular $\mathrm{Ca}^{2+}$ overload.

In conclusion, noscapine, a non-toxic alkaloid from opium, protected the OLN-93 oligodendrocytes during time-scheduled ischemia-induced damage. Additionally, noscapine significantly attenuated the intracellular $\mathrm{Ca}^{2+}$ elevation during chemical oxygen-glucose deprivation, and significantly decreased the production of NO during 30 minutes of oxygenglucose deprivation/reperfusion. These observations support the hypothesis that $\mathrm{Ca}^{2+}$ current and NO production during ischemic insult, have a role in causing cell damage. The potent inhibitory effect on intracellular $\mathrm{Ca}^{2+}$ overload by noscapine, compared with its weaker inhibition on NO production, seems to be the key mechanism for inhibition of ischemiainduced excitotoxicity in oligodendrocytes although the detailed mechanism should be investigated. Thus, noscapine in nontoxic concentrations may be considered as an effective agent to reduce ischemia-induced excitotoxic injury in oligodendroglial cells.

\section{Acknowledgement}

We would like to thank Dr. Massoud Mahmoudian for his consideration and organizing the facilities for this study.

\section{REFERENCES}

1. Barreto-Chang OL, Dolmetsch RE: Calcium imaging of cortical neurons using fura-2 AM. M. J. Vis. Exp. 23, e1067 (2009)

2. Brown GC: Nitric oxide and neuronal death. Nitric Oxide 23, 153-165 (2010)

3. Bsibsi M, Nomden A, van Noort JM, Baron W: Toll-like receptors 2 and 3 agonists differentially affect oligodendrocyte survival, differentiation, and myelin membrane formation. J. Neurosci. Res. 90, 388-398 (2012)

4. Buckinx R, Smolders I, SahebAlia S, Janssen D, Smets I, Ameloot M, Rigo JM: Morphological changes do not reflect biochemical and functional differentiation in OLN-93 oligodendroglial cells. J. Neurosci. Methods. 184, 1-9 (2009)

5. Dang TT, Facchini PJ: Characterization of three O-methyltransferases involved in noscapine biosynthesis in opium poppy. Plant Physiol. 159, 618-631 (2012)

6. Deng W, Wang H, Rosenberg PA, Volpe JJ, Jensen FE: Role of metabotropic glutamate receptors in oligodendrocyte excitotoxicity and oxidative stress. Proc. Natl. Acad. Sci. USA 101, 7751-7756 (2004)

7. Follett PL, Deng W, Dai W, Talos DM, Massillon LJ, Rosenberg PA, Volpe JJ, Jensen FE: Glutamate receptormediated oligodendrocyte toxicity in periventricular leukomalacia: a protective role for topiramate. J. Neurosci. 24, 4412-4420 (2004)

8. Frandsen A, Drejer J, Schousboe A: Direct evidence that excitotoxicity in cultured neurons is mediated via N-methyl-D-aspartate (NMDA) as well as non-NMDA receptors. J. Neurochem. 53, 297-299 (1989)

9. Frantseva MV, Carlen PL, El-Beheiry H: A submersion method to induce hypoxic damage in organotypic hippocampal cultures. Neurosci. Methods 89, 25-31 (1999)

10. Giaume C, Kirchhoff F, Matute C, Reichenbach A, Verkhratsky A: Glia: the fulcrum of brain diseases. Cell Death Differ. 14, 1324-1335 (2007)

11. Gurusamy N, Lekli I, Gorbunov NV, Gherghiceanu M, Popescu LM, Das DK: Cardioprotection by adaptation to ischaemia augments autophagy in association with BAG-1 protein. J. Cell Mol. Med. 13, 373-387 (2009) 
12. Heidari N, Goliaei B, Moghaddam PR, Rahbar-Roshandel N, Mahmoudian M: Apoptotic pathway induced by noscapine in human myelogenous leukemic cells. Anticancer Drugs 18, 1139-1147 (2007)

13. Hiser L, Herrington B, Lobert S: Effect of noscapine and vincristine combination on demyelination and cell proliferation in vitro. Leuk. Lymphoma 49, 1603-1609 (2008)

14. Jung YJ, Suh EC, Lee KE: Oxygen/glucose deprivation and reperfusion cause modifications of postsynaptic morphology and activity in the CA3 area of arganotypic hippocampal slice cultures. Korean J. Physiol. Pharmacol. 16, 423-429 (2012)

15. Káradóttir R, Cavelier P, Bergersen LH, Attwell D: NMDA receptors are expressed in oligodendrocytes and activated in ischaemia. Nature 438, 1162-1166 (2005)

16. Katnik C, Guerrero WR, Pennypacker KR, Herrera Y, Cuevas J: Sigma-1 receptor activation prevents intracellular calcium dysregulation in cortical neurons during in vitro ischemia. J. Pharmacol. Exp. Ther. 319, 1355-1365 (2006)

17. Kaur C, Sivakumar V, Ang LS, Sundaresan A: Hypoxic damage to the periventricular white matter in neonatal brain: role of vascular endothelial growth factor, nitric oxide and excitotoxicity. J. Neurochem. 98, 1200-1216 (2006)

18. Kew JN, Kemp JA: Ionotropic and metabotropic glutamate receptor structure and pharmacology. Psychopharmacology (Berl) 179, 4-29 (2005)

19. Khanmoradi M, Ali Mard S, Aboutaleb N, Nobakht M, Mahmoudian M: The protective activity of noscapine on renal ischemia-reperfusion injury in male Wistar rat. Iran J. Basic Med. Sci. 17, 244-249 (2014)

20. Knott AB, Bossy-Wetzel E: Nitric oxide in health and disease of the nervous system. Antioxid. Redox. Signal. 11, 541-554 (2009)

21. Knyihár-Csillik E, Okuno E, Vécsei L: Effects of in vivo sodium azide administration on the immunohistochemical localization of kynurenine aminotransferase in the rat brain. Neuroscience 94, 269-277 (1999)

22. Koh JY, Goldberg MP, Hartley DM, Choi DW: Non-NMDA receptor-mediated neurotoxicity in cortical culture. J. Neurosci. 10, 693-705 (1990)

23. Kolodziejczyk K, Saab AS, Nave KA, Attwell D: Why do oligodendrocyte lineage cells express glutamate receptors? F1000 Biol. Rep. 2, 57 (2010)

24. Kowara R, Moraleja KL, Chakravarthy B: Involvement of nitric oxide synthase and ROS-mediated activation of L-type voltage-gated $\mathrm{Ca}^{2+}$ channels in NMDA-induced DPYSL3 degradation. Brain Res. 1119, 40-49 (2006)

25. Lecht S, Rotfeld E, Arien-Zakay H, Tabakman R, Matzner H, Yaka R, Lelkes PI, Lazarovici P: Neuroprotective effects of nimodipine and nifedipine in the NGF-differentiated PC12 cells exposed to oxygen-glucose deprivation or trophic withdrawal. Int. J. Dev. Neurosci. 30, 465-469 (2012)

26. Lekli I, Szabo G, Juhasz B, Das S, Das M, Varga E, Szendrei L, Gesztelyi R, Varadi J, Bak I, Das DK, Tosaki A: Protective mechanisms of resveratrol against ischemia-reperfusion-induced damage in hearts obtained from Zucker obese rats: the role of GLUT-4 and endothelin. Am. J. Physiol. Heart Circ. Physiol. 294, H859-H866 (2008)

27. Li S, He J, Li S, Cao G, Tang S, Tong Q, Joshi HC: Noscapine induced apoptosis via downregulation of survivin in human neuroblastoma cells having wild type or null p53. PLoS One 7, e40076 (2012)

28. Mahad DJ, Ziabreva I, Campbell G, Lax N, White K, Hanson PS, Lassmann H, Turnbull DM: Mitochondrial changes within axons in multiple sclerosis. Brain 132, 1161-1174 (2009)

29. Mahmoudian M, Mojaverian N: Effect of noscapine, the antitussive opioid alkaloid, on bradykinin-induced smooth muscle contraction in the isolated ileum of the guinea-pig. Acta Physiol. Hung. 88, 231-237 (2001)

30. Mahmoudian M, Rahimi-Moghaddam P: The anti-cancer activity of noscapine: a review. Recent Pat. Anticancer Drug Discov. 4, 92-97 (2009)

31. Mahmoudian M, Mehrpour M, Benaissa F, Siadatpour Z: A preliminary report on the application of noscapine in the treatment of stroke. Eur. J. Clin. Pharmacol. 59, 579-581 (2003)

32. Mahmoudian M, Siadatpour Z, Ziai SA, Mehrpour M, Benaissa F, Nobakht M: Reduction of the prenatal hypoxic-ischemic brain edema with noscapine. Acta Physiol. Hung. 90, 313-318 (2003)

33. Marino S, Marani L, Nazzaro C, Beani L, Siniscalchi A: Mechanisms of sodium azide-induced changes in intracellular calcium concentration in rat primary cortical neurons. Neurotoxicology 28, 622-629 (2007)

34. Matute C: Oligodendrocyte NMDA receptors: a novel therapeutic target. Trends Mol. Med. 12, 289-292 (2006)

35. Matute C: Calcium dyshomeostasis in white matter pathology. Cell Calcium 47, 150-157 (2010)

36. Matute C, Alberdi E, Domercq M, Pérez-Cerdá F, Pérez-Samartín A, Sánchez-Gómez MV: The link between excitotoxic oligodendroglial death and demyelinating diseases. Trends Neurosci. 24, 224-230 (2001)

37. Matute C, Alberdi E, Ibarretxe G, Sánchez-Gómez MV: Excitotoxicity in glial cells. Eur. J. Pharmacol. 447, $239-246(2002)$ 
38. Matute C, Alberdi E, Domercq M, Sánchez-Gómez MV, Pérez-Samartín A, Rodríguez-Antigüedad A, PérezCerdá F: Excitotoxic damage to white matter. J. Anat. 210, 693-702 (2007)

39. Moncada C, Lekieffre D, Arvin B, Meldrum B: Effect of NO synthase inhibition on NMDA- and ischaemiainduced hippocampal lesions. Neuroreport 3, 530-532 (1992)

40. Mosmann T: Rapid colorimetric assay for cellular growth and survival: application to proliferation and cytotoxicity assays. J. Immunol. Methods 65, 55-63 (1983)

41. Pitt D, Werner P, Raine CS: Glutamate excitotoxicity in a model of multiple sclerosis. Nat. Med. 6, 67-70 (2000)

42. Rahbar-Roshandel N, Razavi L, Tavakoli-Far B, Mahmoudian M: Mebudipine and dibudipine protect PC12 cells against oxygen-glucose deprivation and glutamate-induced cell death. Pathophysiology 15, 227-231 (2008)

43. Richter-Landsberg C, Heinrich M: OLN-93: a new permanent oligodendroglia cell line derived from primary rat brain glial cultures. J. Neurosci. Res. 45, 161-173 (1996)

44. Ruiz A, Matute $\mathrm{C}$, Alberdi E: Intracellular $\mathrm{Ca}^{2+}$ release through ryanodine receptors contributes to AMPA receptor-mediated mitochondrial dysfunction and ER stress in oligodendrocytes. Cell Death Dis. 1, e54. (2010)

45. Salter MG, Fern R: NMDA receptors are expressed in developing oligodendrocyte processes and mediate injury. Nature 438, 1167-1171 (2005)

46. Selvatici R, Previati M, Marino S, Marani L, Falzarano S, Lanzoni I, Siniscalchi A: Sodium azide induced neuronal damage in vitro: evidence for non-apoptotic cell death. Neurochem. Res. 34, 909-916 (2009)

47. Seo-Mayer PW, Thulin G, Zhang L, Alves DS, Ardito T, Kashgarian M, Caplan MJ: Preactivation of AMPK by metformin may ameliorate the epithelial cell damage caused by renal ischemia. Am. J. Physiol. Renal Physiol. 301, F1346-F1357 (2011)

48. Singh H, Singh P, Kumari K, Chandra A, Dass SK, Chandra R: A review on noscapine, and its impact on heme metabolism. Curr. Drug Metab. 14, 351-360 (2013)

49. Sloane JA, Batt C, Ma Y, Harris ZM, Trapp B, Vartanian T: Hyaluronan blocks oligodendrocyte progenitor maturation and remyelination through TLR2. Proc. Natl. Acad. Sci. USA 107, 11555-11560 (2010)

50. Szatmary Z: Molecular biology of toll-like receptors. Gen. Physiol. Biophys. 31, 357-366 (2012)

51. Szydlowska K, Tymianski M: Calcium, ischemia and excitotoxicity. Cell Calcium 47, 122-129 (2010)

52. Tavakoli-Far B, Rahbar-Roshandel N, Rahimi-Moghaddam P, Mahmoudian M: Neuroprotective effects of mebudipine and dibudipine on cerebral oxygen-glucose deprivation/reperfusion injury. Eur. J. Pharmacol. 610, 12-17 (2009)

53. Tosaki A, Balint S, Szekeres L: Protective effect of lidocaine against ischemia and reperfusion-induced arrhythmias and shifts of myocardial sodium, potassium, and calcium content. J. Cardiovasc. Pharmacol. 12, 621-628 (1988)

54. Tsien RY, Rink TJ, Poenie M: Measurement of cytosolic free $\mathrm{Ca}^{2+}$ in individual small cells using fluorescence microscopy with dual excitation wavelengths. Cell Calcium 6, 145-157 (1985)

55. Wang Q, Gong Q, Wu Q, Shi J: Neuroprotective effects of Dendrobium alkaloids on rat cortical neurons injured by oxygen-glucose deprivation and reperfusion. Phytomedicine 17, 108-115 (2010)

56. Wang Y, Qin ZH: Molecular and cellular mechanisms of excitotoxic neuronal death. Apoptosis 15, 1382-1402 (2010)

57. Wang ZJ, Li GM, Tang WL, Yin M: Neuroprotective effects of stearic acid against toxicity of oxygen/glucose deprivation or glutamate on rat cortical or hippocampal slices. Acta Pharmacol. Sin. 27, 145-150 (2006)

58. Wilkins A, Majed H, Layfield R, Compston A, Chandran S: Oligodendrocytes promote neuronal survival and axonal length by distinct intracellular mechanisms: a novel role for oligodendrocyte-derived glial cell linederived neurotrophic factor. J. Neurosci. 23, 4967-4974 (2003)

59. Yao S, Pandey P, Ljunggren-Rose A, Sriram S: LPS mediated injury to oligodendrocytes is mediated by the activation of nNOS: relevance to human demyelinating disease. Nitric Oxide 22, 197-204 (2010)

60. Yao SY, Ljunggren-Rose A, Chandramohan N, Whetsell WO Jr, Sriram S: In vitro and in vivo induction and activation of nNOS by LPS in oligodendrocytes. J. Neuroimmunol. 229, 146-156 (2010)

61. Ye K, Ke Y, Keshava N, Shanks J, Kapp JA, Tekmal RR, Petros J, Joshi HC: Opium alkaloid noscapine is an antitumor agent that arrests metaphase and induces apoptosis in dividing cells. Proc. Natl. Acad. Sci. USA 95, 1601-1606 (1998)

62. Ziabreva I, Campbell G, Rist J, Zambonin J, Rorbach J, Wydro MM, Lassmann H, Franklin RJ, Mahad D: Injury and differentiation following inhibition of mitochondrial respiratory chain complex IV in rat oligodendrocytes. Glia 58, 1827-1837 (2010) 